\title{
Expression and Circulating Levels of Perlecan in Breast Cancer - Implications for Oestrogen Dependent Stromal Remodeling
}

\author{
Malin Jansson $^{1}$ (1) - Ola Billing ${ }^{1} \cdot$ Carl Herdenberg $^{2} \cdot$ Christina Lundin $^{1} \cdot$ Egle Tolockiene $^{3} \cdot$ Anoosheh Nazemroaya $^{3}$. \\ Malin Sund ${ }^{1}$
}

Received: 25 September 2019 / Accepted: 18 February 2020 / Published online: 2 March 2020

(C) The Author(s) 2020

\begin{abstract}
Localised breast cancer can be cured by surgery and adjuvant treatments, but mortality remains high as some tumours metastasize early. Perlecan is a basement membrane (BM) protein involved in tumour development and progression. Here, mRNA and protein expression of perlecan, and mRNA expression of matrix degrading enzymes were studied in normal breast and invasive breast cancer, and correlated to prognostic risk factors, in particular oestrogen status. Moreover, plasma levels of perlecan were measured in patients with breast cancer and compared with controls. mRNA data was extracted from the Cancer Genome Atlas database. Perlecan protein expression was visualized using immunofluorescence and plasma levels measured by ELISA assay. Perlecan mRNA levels were twice as high in normal breast compared with breast cancer tissue. A strong correlation was found between mRNA expression of perlecan and several matrix-degrading enzymes in oestrogen receptor positive (ER+) tumours. Perlecan protein was localized to both epithelial and vascular BMs, but absent in the stroma in normal breast. In breast cancer, the expression of perlecan in epithelial BM was fragmented or completely lost, with a marked upregulation of perlecan expression in the stroma. Significantly higher levels of perlecan were found in plasma of ER+ patients when compared with ER- patients. This study shows that perlecan expression and degradation in breast cancer may be linked to the ER status of the tumour.
\end{abstract}

Keywords Perlecan $/ H S P G 2 \cdot$ Breast cancer $\cdot$ Oestrogen receptor, extracellular matrix $\cdot$ Matrix metalloproteinases

\section{Introduction}

Several prognostic and treatment predictive biomarkers are routinely used to categorize patients with breast cancer (BC). These factors include patient age, axillary lymph node status, tumour size, histological grade, lymphovascular invasion, hormone receptor status, HER2 status and proliferation

Electronic supplementary material The online version of this article (https://doi.org/10.1007/s10911-020-09447-2) contains supplementary material, which is available to authorized users.

Malin Jansson

malin.jansson@umu.se

1 Department of Surgery and Perioperative Sciences/Surgery, Umeå University, 90185 Umeå, Sweden

2 Department of Radiation Sciences/Oncology, Umeå University, 90185 Umeå, Sweden

3 Department of Medical Biosciences/Pathology, Umeå University, 90185 Umeå, Sweden measured by $\mathrm{Ki}-67$. In recent years, gene expression profiling and molecular subtyping of $\mathrm{BC}$ has further been used to help refine classification and guide decisions about therapy [1]. Most of the current factors used are based on the properties of the malignantly transformed epithelial cell. Cancer cells do however not grow in isolation. Increasing evidence show that the stroma actively participates in tumour formation [2]. Tumour stroma shares many similarities with granulation tissue and scar formation in wound healing, and cancers have been described as wounds that do not heal [3].

In $\mathrm{BC}$, the tumour stroma differs from the normal stroma by an increased deposition of extracellular matrix (ECM) molecules such as type I, III, and V collagen, fibronectin, laminins, glycosaminoglycans, proteoglycans and matricellular proteins, which all collectively alter the structure and stiffness of the stroma. Stromal proteolysis by matrix metalloproteinases (MMPs) is also increased, leading to matrix fragmentation, which provides room and migration paths for cancer cells. BC stroma also produces growth factors, modulates surface receptors, causes fibroblasts to proliferate and stimulates the release of matrix regulatory proteins. This 
stromal remodelling is necessary to satisfy the needs of the growing tumour, promote metastasis and contributes to tumour resistance to systemic treatments [4].

The basement membrane (BM) separates the epithelial cells from the surrounding stroma in all glandular epithelium. Perlecan, also known as heparan sulfate proteoglycan 2 (HSPG2), is a large BM molecule, which forms a complex network with laminin, nidogen, type IV, XV, and XVIII collagen, and other ECM molecules [5-9]. Perlecan mediates cell-matrix adhesion, interacts with other molecules $[10,11]$, sequesters and releases growth factors [12-14], stimulates cell growth and differentiation [15], and furthermore regulates the vascular response to injury [16]. Due its multifunctional roles, perlecan is proposed to act as a border separating tissues during development, tissue formation and wound healing [17]. Domain V, the C-terminal of perlecan, also known as endorepellin, can inhibit $[18,19]$ angiogenesis, and in the context of cancer remodelling, has opposite effects to perlecan [20]. Moreover, further bioactive substances can be released from endorepellin by bone morphogenic protein-1 (BMP1) [21] and cathepsin L (CTSL) [22].

The aim of the present study was to investigate the mRNA and protein expression of perlecan, and mRNA expression of matrix degrading enzymes in normal breast and breast cancer tissue, and analyse whether there is a correlation to known prognostic biomarkers. Moreover, circulating levels of released perlecan were measured in plasma from breast cancer patients both pre- and postoperatively.

\section{Materials and Methods}

\section{Study Cohorts}

In the present study three different patient cohorts were used (cohort I-III). Data for cohort I was obtained through the Cancer Genome Atlas (TCGA) [23]. All patients in cohort II and III were admitted for elective surgery to the Department of Surgery, Umeå University Hospital during the years 20082012. Informed consent was obtained from all patients, and the ethical committee at the Medical faculty of Umeå University approved the study.

\section{Study Cohorts for the Gene Expression Data from TCGA (Cohort I)}

The mRNA expression of perlecan and matrix degrading enzymes matrix metalloproteinases (MMPs) 1-3, 7-17, 19-21, 23A, 23B, 24, 25, 27, 28, BMP1, cathepsin L (CTSL) and cathepsin V (CTSV) were analysed in cohort I obtained from the Cancer Genome Atlas (TCGA). This database contains mRNA sequence data and clinicopathological data. Clinical data and fragments per kilo base of transcript per million mapped reads at upper quartile (FPKM-UQ) from all the available primary breast cancer patients in TCGA $(n=1089)$ and from normal breast tissue from 108 of these patients was extracted. The FPKM-UQ data is generated by first aligning RNA-Seq reads with a reference genome followed by normalization using the FPKM-UQ method. (https://docs.gdc.cancer. gov/Data/Bioinformatics_Pipelines/Expression_mRNA_ Pipeline/) The database was last updated 29:e of January 2017. Patient characteristics of cohort I are summarized in Table 1.

\section{Study Cohorts for Protein Expression and Circulating Perlecan (Cohorts II and III)}

The cohorts were selected from a larger prospectively kept biobank, based on the availability of samples and with the aim to obtain an equal distribution of invasive ductal $\mathrm{BC}$ with

Table 1 Patient characteristics of cohort I

\begin{tabular}{|c|c|c|}
\hline & \multicolumn{2}{|c|}{ Cohort I $(n=1089)$} \\
\hline \multicolumn{3}{|l|}{ Age } \\
\hline$\leq 50$ & 328 & $30,1 \%$ \\
\hline $51-60$ & 272 & $25,0 \%$ \\
\hline$\geq 61$ & 489 & $44,9 \%$ \\
\hline \multicolumn{3}{|l|}{ Tumorsize } \\
\hline$\leq 20 \mathrm{~mm}$ & 278 & $25,5 \%$ \\
\hline $21-50 \mathrm{~mm}$ & 631 & $57,9 \%$ \\
\hline$>50 \mathrm{~mm}$ & 177 & $16,3 \%$ \\
\hline Missing & 3 & $0,3 \%$ \\
\hline \multicolumn{3}{|l|}{ Nodestatus } \\
\hline Positive & 453 & $41,6 \%$ \\
\hline Negative & 469 & $43,1 \%$ \\
\hline Missing & 167 & $15,3 \%$ \\
\hline \multicolumn{3}{|c|}{ Preogesteron Receptor } \\
\hline Positive & 695 & $63,8 \%$ \\
\hline Negative & 342 & $31,4 \%$ \\
\hline Missing & 52 & $4,8 \%$ \\
\hline \multicolumn{3}{|c|}{ Estrogen Receptor } \\
\hline Positive & 803 & $73,7 \%$ \\
\hline Negative & 237 & $21,8 \%$ \\
\hline Missing & 49 & $4,5 \%$ \\
\hline \multicolumn{3}{|c|}{ HER2 Receptor } \\
\hline Positive & 90 & $8,3 \%$ \\
\hline Negative & 529 & $48,6 \%$ \\
\hline Missing & 470 & $43,2 \%$ \\
\hline \multicolumn{3}{|l|}{ Tumor type } \\
\hline Ductal & 778 & $71,4 \%$ \\
\hline Lobular & 203 & $18,6 \%$ \\
\hline Others & 107 & $9,8 \%$ \\
\hline Missing & 1 & $0,2 \%$ \\
\hline
\end{tabular}


and without DCIS, node positive and negative, HER2 receptor positive and negative, and hormone receptor positive and negative tumours in both cohorts. The molecular subtype classification was made using the criteria according to the guidelines of St Gallen international Expert Concensus [24]. None of the breast cancer patients had received neoadjuvant radioor chemotherapy.

For cohort II, fresh frozen tumour tissue samples were collected from 31 female BC patients. The patient characteristics are summarized in Table 2. Control tissue samples were obtained from 20 female patients operated for benign breast disease or taken from the periphery of mastectomy specimens. The tissue samples were snap frozen in liquid nitrogen and stored at $-80^{\circ} \mathrm{C}$ until analysis.

For cohort III, plasma samples were collected from 75 BC patients. For $65(86,7 \%)$ patients a preoperative plasma sample was collected, and for $65(86,7 \%)$ a postoperative plasma sample was collected 4-8 weeks after surgery. Patient characteristics are summarized in Table 2. Plasma samples from eight control patients were obtained from female patients undergoing elective surgery for non-malignant diseases. All plasma samples were frozen at $-80^{\circ} \mathrm{C}$ until analysis.

\section{Immunohistochemistry and Antibodies}

Haematoxylin and eosin (H\&E) staining was performed according to standard protocols on frozen sections. For immunofluroscence analysis, $5 \mu \mathrm{m}$ frozen sections were fixed in cold $\left(-20^{\circ} \mathrm{C}\right)$ acetone for $10 \mathrm{~min}$ and then airdried. The slides were washed with PBS and blocked with PBS containing 3\% bovine serum albumin (BSA) at room temperature (RT) for $1 \mathrm{~h}$. Primary antibodies were diluted using 3\% BSA/PBS, applied to the sections, and incubated for $1 \mathrm{~h}$ at RT in a humid chamber. The primary antibodies and dilutions used were goat anti-human endorepellin (R\&D systems, Minneapolis, MN, USA; AF2364, 1:100) and mouse antihuman cytokeratin 18 (DakoCytomation, Glosstrup, Denmark; clone DC10, M7010, 1:50). The slides were then washed and incubated with secondary antibodies diluted at $1: 100$ in $3 \%$ BSA/PBS for $1 \mathrm{~h}$ at RT in a dark chamber. The secondary antibodies used were: donkey anti-goat TRITC and donkey anti-mouse FITC (both from Jackson ImmunoResearch Laboratories, Inc., West Grove, PA, USA). After washing with PBS, sections were mounted with DAPI hard set medium (Vectashield, Vector Laboratories Inc., Burlingame, CA, USA).

\section{Elisa Assay}

Circulating levels of perlecan in plasma were measured using commercial HSPG2 (perlecan) ELISA kit (Cloud-Clone Corp, Wuhan, Hubei, PRC; Product no. SEC748Hu) according to the manufacturers' protocol. The samples were
Table 2 Patient characteristics of cohort II and III

\begin{tabular}{|c|c|c|c|c|}
\hline & \multicolumn{2}{|c|}{ Cohort II $(n=31)$} & \multicolumn{2}{|c|}{ Cohort III $(n=75)$} \\
\hline \multicolumn{5}{|l|}{ Age } \\
\hline$\leq 50$ & 11 & $35,5 \%$ & 21 & $28,0 \%$ \\
\hline $51-60$ & 5 & $16,1 \%$ & 16 & $21,3 \%$ \\
\hline$\geq 61$ & 15 & $48,4 \%$ & 38 & 50,7 \\
\hline \multicolumn{5}{|l|}{ Tumour size } \\
\hline$\leq 20 \mathrm{~mm}$ & 10 & $27,8 \%$ & 41 & $54,7 \%$ \\
\hline $21-50 \mathrm{~mm}$ & 19 & $66,7 \%$ & 30 & $40,0 \%$ \\
\hline$>50 \mathrm{~mm}$ & 2 & $5,6 \%$ & 4 & $5,3 \%$ \\
\hline \multicolumn{5}{|l|}{ Nodal status } \\
\hline Positive & 16 & $51,6 \%$ & 43 & $57,3 \%$ \\
\hline Negative & 15 & $48,4 \%$ & 32 & $42,7 \%$ \\
\hline \multicolumn{5}{|l|}{ Tumour grade } \\
\hline 1 & 4 & $12,9 \%$ & 14 & $18,7 \%$ \\
\hline 2 & 7 & $22,6 \%$ & 17 & $22,7 \%$ \\
\hline 3 & 20 & $64,5 \%$ & 44 & $58,7 \%$ \\
\hline \multicolumn{5}{|l|}{ IDC mixed with DCIS } \\
\hline Yes & 16 & $51,6 \%$ & 31 & $41,3 \%$ \\
\hline No & 15 & $48,4 \%$ & 44 & $58,7 \%$ \\
\hline \multicolumn{5}{|l|}{ Oestrogen Receptor } \\
\hline Positive & 17 & $54,8 \%$ & 44 & $58,7 \%$ \\
\hline Negative & 14 & $45,2 \%$ & 31 & $41,3 \%$ \\
\hline \multicolumn{5}{|l|}{ Progesteron Receptor } \\
\hline Positive & 15 & $48,4 \%$ & 40 & $53,3 \% \%$ \\
\hline Negative & 16 & $51,6 \%$ & 35 & $46,7 \%$ \\
\hline \multicolumn{5}{|l|}{ HER2 Receptor } \\
\hline Positive & 12 & $38,7 \%$ & 29 & $38,7 \%$ \\
\hline Negative & 19 & $61,3 \%$ & 46 & $61,3 \%$ \\
\hline \multicolumn{5}{|l|}{ Ki67 status } \\
\hline Low $(<20 \%)$ & 6 & $19,4 \%$ & 23 & $30,7 \%$ \\
\hline $\operatorname{High}(<20 \%)$ & 25 & $80,6 \%$ & 52 & $69,3 \%$ \\
\hline \multicolumn{5}{|l|}{ Molecular subtype } \\
\hline Luminal A & 6 & $19,4 \%$ & 16 & $21,3 \%$ \\
\hline Luminal B (HER2 nega & 6 & $19,4 \%$ & 16 & $21,3 \%$ \\
\hline Luminal B (HER2 posi & 5 & $16,1 \%$ & 12 & $16,0 \%$ \\
\hline HER2 positive & 7 & $22,6 \%$ & 17 & $22,7 \%$ \\
\hline Triple negative & 7 & $22,6 \%$ & 14 & $18.7 \%$ \\
\hline
\end{tabular}

Abbreviations: IDC = invasive ductal cancer; DCIS = ductal carcinoma in situ

analysed in duplicates and the concentration was determined by comparing the OD $(450 \mathrm{~nm})$ of the samples with the standard curve and final concentration were calculated by multiplying with the dilution factor.

\section{Statistics}

SPSS version 24 software was used for statistical analysis. To estimate the difference between groups with low numbers the 
Mann-Whitney U test, Wilcoxon test and Spearman's rank correlation test were used since the data was not normally distributed. For normally distributed data, independent and dependent T-test, one-way ANOVA test and linear regression models were used. For survival analyses of perlecan mRNA expression, a cut of value of 750,000 FPKM-UQ was used and selected based on the appearance of the histogram of cohort I.

\section{Results}

\section{Characterization of the Cohorts}

Patient characteristics for cohort I are presented in Table 1 and for cohorts II and III in Table 2.

Cohort I used for mRNA analysis includes 1089 patients with primary $\mathrm{BC}$ and normal breast tissue from a subset of these patients, $108(10,1 \%)$ was used as controls. The mean age for the patients and controls was 58,5 and 56,4 years, respectively. The median follow-up time was two years.

Cohort II was used to analyse protein expression of perlecan in breast tissue and includes 31 patients and 20 controls. Mean age did not differ between the groups, (mean age for patients was 58,29 years and 60,82 years for controls ( $p$ value $=0,59)$ ) and the median follow-up time was almost eight years. Seven out of 31 patients had died of BC related events $(16,1 \%)$ at time of follow-up.

Cohort III was used to analyse perlecan levels in plasma before and after BC surgery. The cohort includes 75 patients and eight controls. The mean age was lower ( $p$ value $=0,034$ ) for the controls ( 49,3 years) than for the patients $(59,2$ years) and the median follow up time for the patients was 8,5 years. Mean age did not differ between the groups and the median follow up time for the patients was 8,5 years. A total of 11 $(14,7 \%)$ patients had died in a BC related event at the time of follow-up. There were ten cases of missing data for perlecan both in the pre- and post-operative group, but these were equally distributed among the different patient subgroups.

There were a higher number of large $(>55 \mathrm{~mm})$ and node positive tumours in cohort I compared with cohorts II and III. There were a low number of HER2 receptor amplified tumours in cohort I, although a lot of missing data for this variable. Molecular subgrouping could thus not be performed for cohort I, as neither the Ki67 variable nor the grade of the tumour were available.

\section{mRNA Levels of Perlecan in Breast Cancer Tissue}

The mRNA expression of perlecan in normal breast was almost twice as high (mean 726,420 FPKM-UQ) compared with the mRNA level in the BC tissue from the same patient (mean 398,101 FPKM-UQ) ( $p$ value
$<0,001)$. Among the $\mathrm{BC}$ patients, there was a significantly higher level of perlecan mRNA expression in ER+ cancer (mean 413,638 FPKM-UQ) compared with ER- cancer (mean 364,610 FPKM-UQ) $(p=0,014)$. The perlecan mRNA level was also higher in progesterone receptor positive $(\mathrm{PR}+$ ) cancer (mean 415,783 FPKMUQ) compared with progesterone receptor negative (PR-) cancer (mean 375,048 FPKM-UQ) $(p=0,022)$ (Fig. 1). There were no significant differences in perlecan mRNA expression levels in relation to age, lymph node status, HER2 amplification or tumour size (Fig. S1 a-d). No association between perlecan mRNA expression and survival was seen $(p$ value $=0,44)$ overall nor when stratifying patients according to ER status $(p$ value $=0,41)($ Fig. S2).

\section{mRNA Levels of Matrix Degrading Enzymes in Breast Cancer Tissue}

The mRNA expression of MMP1, 3, 10-17, 25, BMP 1 and CTSV was significantly higher in BC compared with normal breast tissue. For MMP19, 23A, 27 and 28 the opposite was seen (Table 3). The mRNA expression of MMPs in relation to perlecan mRNA expression showed that the mRNA expression of MMP2-3, 7-8, 10-14, 16, 19, 21, 23B, 25, 27-28, BMP1, CTSL and CTSV correlated significantly with perlecan mRNA expression. In ER+ tumours a significant correlation between perlecan and MMP2, 3, 8, 10-11, 13-14, 16, 17, 19, 21, 23B, 25, 27, 28, BMP1, CTSL and CTSV mRNAs could be seen. In ER- tumours a significant correlation with perlecan and MMP2, 8, 11, 13-14, 19, 21, 27, BMP 1 and CTSV mRNAs were seen (Table S1 and Fig. 2), and thus there were differences between the ER+ and ER- tumours.

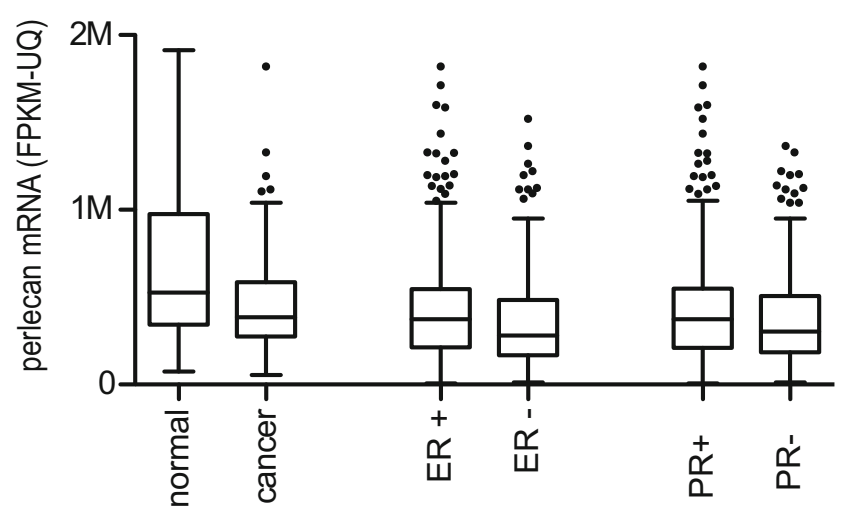

Fig. 1 Perlecan mRNA in breast cancer tissue and normal breast tissue. The mRNA levels of perlecan in the normal breast tissue are almost twice as high as the levels in the breast cancer tissue from the same patient. There is a significantly higher level of perlecan mRNA expression in ER+ breast cancer compared with ER- breast cancer, and the same is shown in $\mathrm{PR}+$ breast cancer compared with PR- breast cancer 
Table 3 mRNA expression of different matrix degrading enzymes in breast cancer. Dependent $\mathrm{T}$ test comparing mean mRNA of different matrix degrading enzymes in breast cancer tissue vs normal breast tissue. NS, not significant

\begin{tabular}{|c|c|c|c|}
\hline & $\begin{array}{l}\text { Normal breast } \\
\text { tissue Mean } \\
\text { (FPKM-UQ) }\end{array}$ & $\begin{array}{l}\text { Breast cancer } \\
\text { tissue Mean } \\
\text { (FPKM-UQ) }\end{array}$ & $p$ value \\
\hline MMP1 & 4994 & 407,074 & $>0,001$ \\
\hline MMP2 & $2,464,000$ & $2,624,000$ & $N S$ \\
\hline MMP3 & 35,969 & 178,997 & $>0,001$ \\
\hline MMP7 & 977,741 & 866,989 & $N S$ \\
\hline MMP8 & 1269 & 2379 & $N S$ \\
\hline ММР9 & 178,137 & $1,804,000$ & $N S$ \\
\hline MMP1 0 & 9057 & 90,455 & $>0,001$ \\
\hline MMP11 & 19,497 & $1,665,000$ & $>0,001$ \\
\hline MMP12 & 16,934 & 72,507 & 0,0053 \\
\hline MMP13 & 3794 & 371,442 & $>0,001$ \\
\hline MMP14 & $1,011,000$ & $2,577,000$ & $>0,001$ \\
\hline MMP15 & 155,952 & 194,402 & 0,0339 \\
\hline MMP16 & 28,542 & 36,863 & 0,0206 \\
\hline MMP17 & 24,353 & 35,792 & 0,0002 \\
\hline MMP19 & 158,355 & 74,854 & $>0,001$ \\
\hline MMP20 & 3474 & 4755 & $N S$ \\
\hline MMP2 1 & 1745 & 1656 & $N S$ \\
\hline MMP23A & 6043 & 4393 & 0,0373 \\
\hline MMP23B & 902 & 709 & $N S$ \\
\hline MMP24 & 24,254 & 18,042 & $N S$ \\
\hline MMP25 & 14,208 & 27,067 & 0,0003 \\
\hline MMP27 & 15,168 & 2684 & $>0,001$ \\
\hline MMP28 & 139,705 & 31,574 & $>0,001$ \\
\hline BMP1 & 88,137 & 125,976 & $>0,001$ \\
\hline CTSL & 923,703 & 931,295 & $N S$ \\
\hline CT S V & 25,652 & 50,784 & 0,0406 \\
\hline
\end{tabular}

Abbreviations: FPKM-UQ = fragments per kilo base of transcript per million mapped reads at upper quartile; $\mathrm{MMP}=$ matrix metalloproteinase; $\mathrm{BMP}=$ bone morphogenetic protein, $\mathrm{CTSL}=$ cathepsin $\mathrm{S} ; \mathrm{CTSV}=$ cathep$\sin \mathrm{V}$

\section{Expression of Perlecan in Breast Cancer Tissue}

In normal breast perlecan protein is localized to both epithelial and vascular BMs and absent in the stroma. In invasive ductal $\mathrm{BC}$ tissue perlecan is lost from epithelial BM, but the expression in the vascular BM remains intact. In cancer an abundant deposition of perlecan protein in the stroma was observed.

A weak correlation between perlecan expression and tumour grade was observed, with high-grade tumours having a stronger expression of perlecan in the stroma (Fig. 3). Perlecan expression did not differ significantly between the different molecular subtypes of $\mathrm{BC}$, nor was there an obvious correlation with oestrogen and/or progesterone receptor expression, node status or tumour size.

\section{Circulation Levels of Perlecan in Plasma}

Circulating levels of perlecan in plasma were measured in controls $(n=8)$ and in patients with $\mathrm{BC}(n=75)$ both before $(n=65)$ and after $(n=65)$ surgery. There was a significantly higher level of perlecan in ER+ breast cancer patients, median $56,8 \mathrm{ng} / \mathrm{ml}$ (preoperative) and median $64,2 \mathrm{ng} / \mathrm{ml}$ (postoperative), compared with ERbreast cancer patients median $47,5 \mathrm{ng} / \mathrm{ml}$ (preoperative) and median $49,0 \mathrm{ng} / \mathrm{ml}$ (postoperative), both in the pre( $p$ value: 0,047$)$ and the post-operative setting ( $\mathrm{p}$ value: 0,007 ) (Fig. 4A). No such difference was observed between HER2+ vs. HER2-, high KI67 (>20\%) vs. low Ki67 $(<20 \%)$, node negative vs. node positive breast cancer patients (Fig. S3 d-f).

There was no significant difference in perlecan plasma levels in the preoperative setting in relation to molecular subtype of the tumour. In the postoperative setting there was a significant difference between the groups, with higher levels of perlecan in plasma in the ER + luminal A (median $65,0 \mathrm{ng} / \mathrm{ml}$ ) and luminal B (HER2 negative) (median $66,3 \mathrm{ng} / \mathrm{ml}$ ) breast cancer compared with the ER- HER2 positive (median $40,5 \mathrm{ng} / \mathrm{ml}$ ) and triple negative (median $55,3 \mathrm{ng} / \mathrm{ml}$ ) breast cancer $(p=0,04)$. The Luminal B (HER2 positive) had a slightly lower level of perlecan than the other $\mathrm{ER}+$ breast cancer groups, (median $52,0 \mathrm{ng} / \mathrm{ml}$ ) but the variance in perlecan level was high among the samples (Fig. 4B).

The pre- and postoperative levels of perlecan in plasma from breast cancer patients did not correlate with age, tumour size or grade (Fig. S3).

\section{Discussion}

Perlecan mRNA was shown here to be twice as high in normal breast compared with $\mathrm{BC}$ tissue. The mRNA levels of several matrix degrading enzymes analysed, were also higher in $\mathrm{BC}$ compared with normal breast tissue, as shown by others before [25]. Interestingly, a strong and significant correlation was observed between the mRNA expression of perlecan and many of the analysed matrix degrading enzymes. In BC tissue significantly higher level of perlecan mRNA was found in ER+ than ER- breast cancer. Moreover, a completely different pattern of correlations between perlecan and matrixdegrading enzyme mRNAs was observed in the ER+ and ER- tumours, indicating differences in stromal remodelling in relation to hormonal receptor status.

Perlecan protein was not localized to the stroma of normal breast tissue, whereas both epithelial and the vascular BMs were intensively stained. In $\mathrm{BC}$ tissue, perlecan protein expression was upregulated in the stroma and fragmented or lost in the epithelial BM, although remaining intact in the vascular $\mathrm{BM}$, indicating that this process is epithelial $\mathrm{BM}$ specific and 


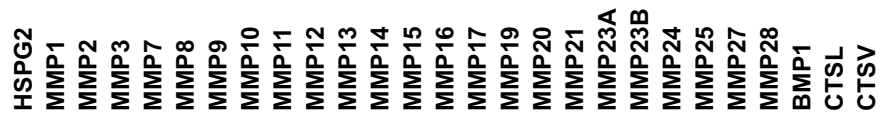

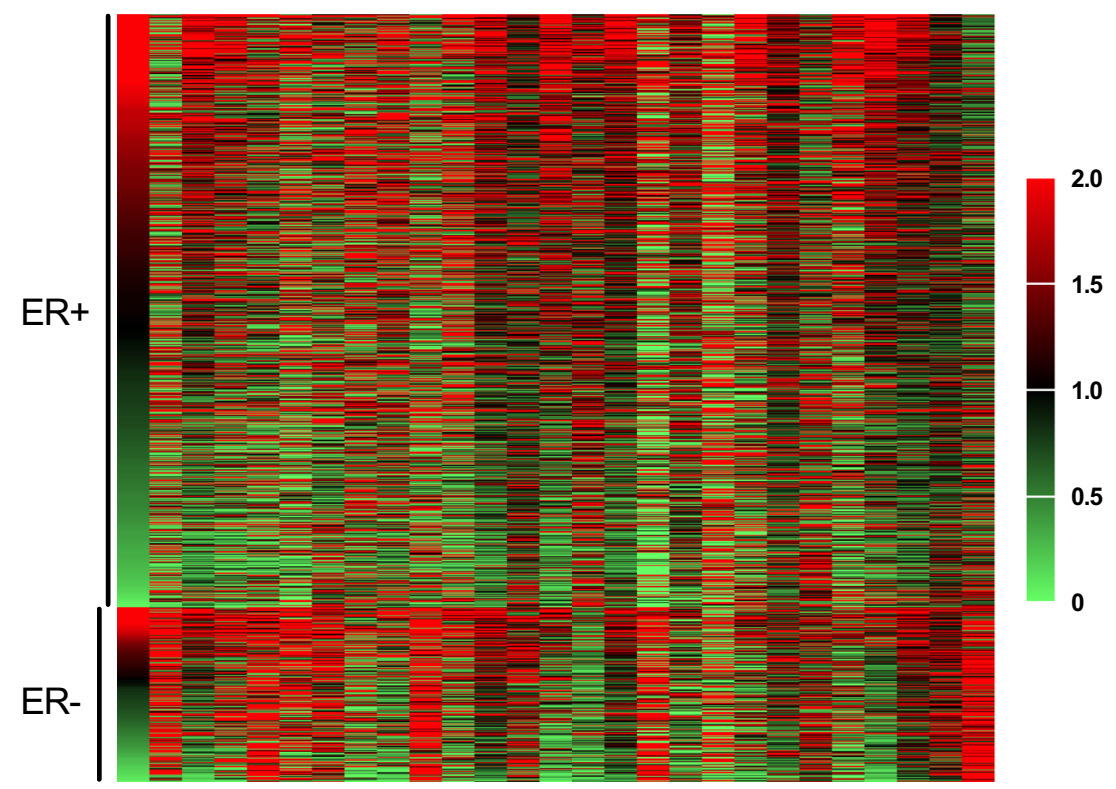

Fig. 2 Heat map of mRNA expression of perlecan and different matrix degrading enzymes. mRNA expression of perlecan and matrix degrading enzymes show a different pattern in ER+ vs ER- breast cancer

may be initiated by the cancer. Perlecan is thus either degraded from its normal tissue location and/or the synthesis of perlecan becomes down-regulated in the BM. It has been recently shown, that the localization of perlecan expression changes from interstitial to predominantly cellular with advancing breast cancer stage, and the intensity of perlecan expression was highest in breast cancer metastasis. This study also showed that higher expression of perlecan at the cell surface correlated with poor survival in triple negative breast cancer [26]. The mRNA analysis showed suppression of expression in breast cancer and similar findings have been made by others. Fernandez Vega et al., showed that perlecan transcript levels were down-regulated 3-fold in non-metastatic invasive ductal breast cancer and close to 6-fold in metastatic tumours [27]. In fibrosarcoma cells, suppression of perlecan expression, resulted in stimulation of tumour cell growth and increased ECM invasion [28]. Moreover, in a cell line derived from Kaposis sarcoma, suppression of perlecan caused enhanced cell migration and proliferation in vitro, and enhanced tumourigenesis and angiogenesis in xenografts [29].

The mRNA expression analysis also showed that the mRNA of MMP1, 3, 10-17, 25, BMP 1 and CTSV were expressed at much higher levels in $\mathrm{BC}$ compared with normal breast tissue. MMPs are well studied and shown to facilitate cancer progression by degrading the BM allowing cancer cells to invade into the surrounding stroma [30]. At least MMP 3, 13, BMP 1 and cathepsin L have been shown to cleave perlecan to varying extents $[14][21,22]$ and thus enhanced cleavage of perlecan is also a possible result of a degraded BM in breast cancer.

In the present study mRNA expression of MMP $2-3,7-8$, 10-14, 16, 19, 21, 23B, 25, 27-28, BMP1, CTSL and CTSV correlated significantly with perlecan mRNA expression indicating that there might be a coupled regulation. Whitelock et al. have showed that proteases can release growth factors from perlecan, and that this may facilitate tumour growth [14]. Moreover, endorepellin generated by proteolysis of perlecan, has been shown to evoke autophagy of endothelial cells [31]. Autophagy, is an alternative energy source and it may confer as a survival advantage on tumour cells under stress [32]. Taken together, this supports an interaction between perlecan and matrix degrading enzymes that could favour tumour growth.

In the breast cancer stroma, the perlecan expression became strong, while it was virtually absent from normal breast stroma. This phenomenon, with deposition of perlecan in the stroma, has been described in other tumours such as colon cancer and oral squamous cell cancer [33, 34], and also in wound healing [35]. Perlecan is synthesised in the stroma by both myofibroblasts and cancer cells [36] and due to its proangiogenic properties [37], a high expression of perlecan in the stroma would support new capillary formation during tumour growth. This, together with the capacity for growth factor binding by perlecan [12-14], with receptor activation [38] and protection of proteolysis of angiogenic growth factors [39], would support further tumour growth and spread. A 


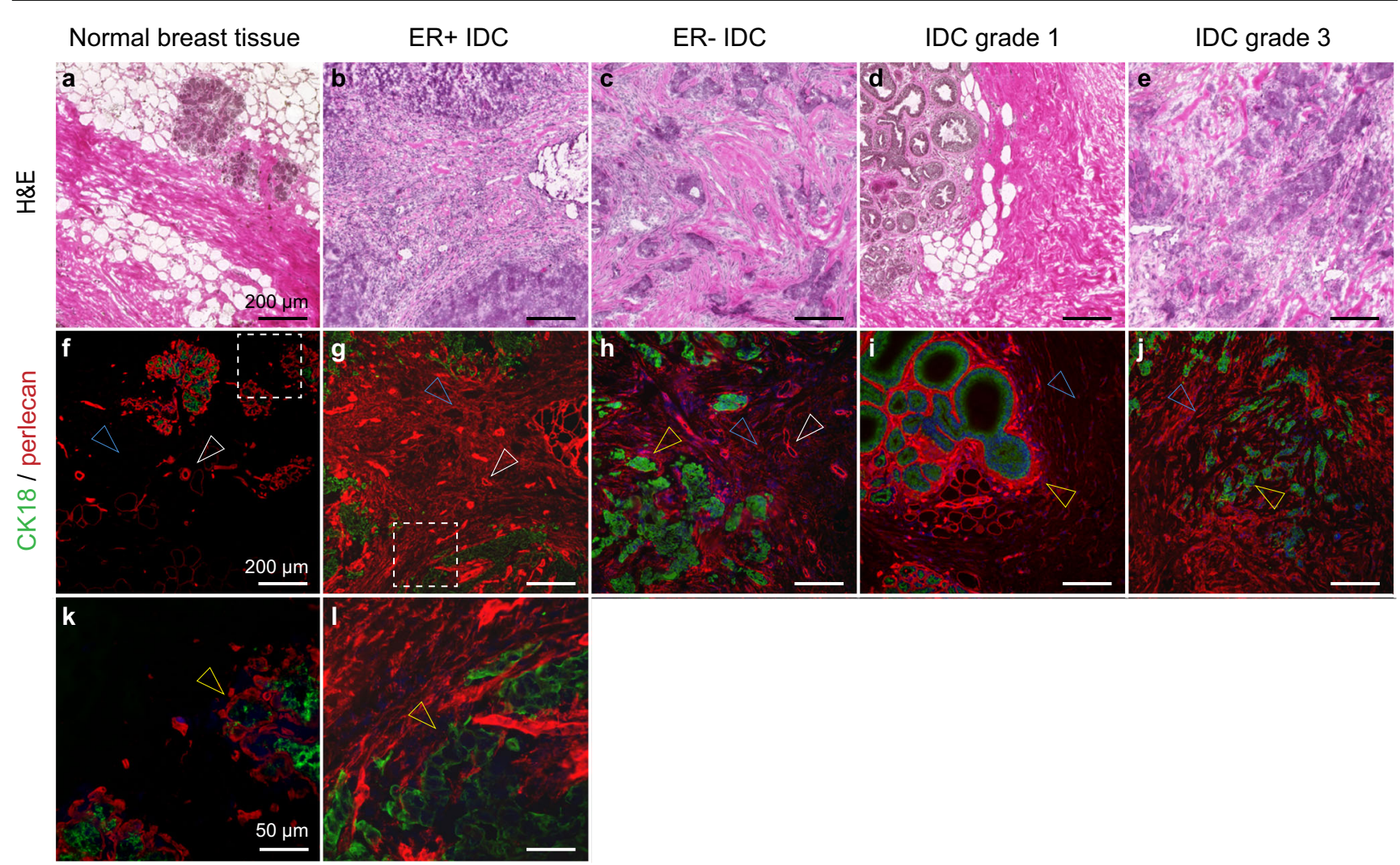

Fig. 3 Immunohistochemistry of perlecan. a-e: Light microscopy images stained with $\mathrm{H} \& \mathrm{E}$ visualized a: normal breast tissue, b: ER+ ductal breast cancer tissue, c: ER- ductal breast cancer tissue, d: invasive ductal cancer tissue grade 1 (IDC1) and e: grade 3 (IDC3). f-1: Immunofluorescence staining, with perlecan (in red) and the epithelial cell marker cytokeratin 18 (in green). f\&k: normal breast tissue showing perlecan expression in both epithelial (yellow arrow) and vascular (white arrow) BMs and no expression in the stroma (blue arrow). g\&l: ER+ and h: ER- invasive ductal breast cancer tissue showing high expression of perlecan in the tumour stroma (blue arrow) and in the vascular BM (white arrow) but no expression in the epithelial BM (yellow arrow). No clear difference in perlecan expression between ER+ and ER- breast cancer can be seen. i: IDC1 tissue showing moderate expression of perlecan in the stroma (blue arrow) and high expression in the epithelial BMs (yellow arrow) that are preserved. j: IDC3 tissue showing strong expression of perlecan in the tumour stroma (blue arrow) and no remaining expression in the epithelial $\mathrm{BM}$ (yellow arrow)
Fig. 4 Plasma levels of perlecan in breast cancer patients and controls. a: Significantly higher levels of perlecan in plasma in ER+ compared with ER- breast cancer patients both pre- and the post-operatively. $b$ : The pre- and postoperative levels of perlecan in plasma in patients with different molecular subtypes of breast cancer. The difference in plasma levels of perlecan between the groups is significant in the postoperative setting with higher levels in patients with luminal tumours

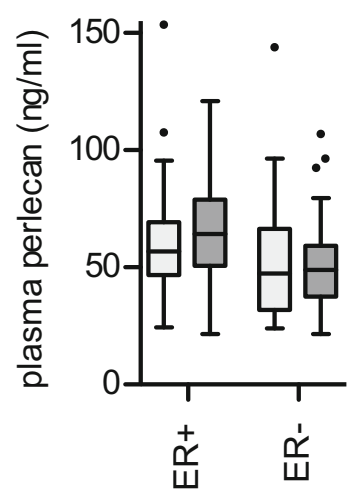

b

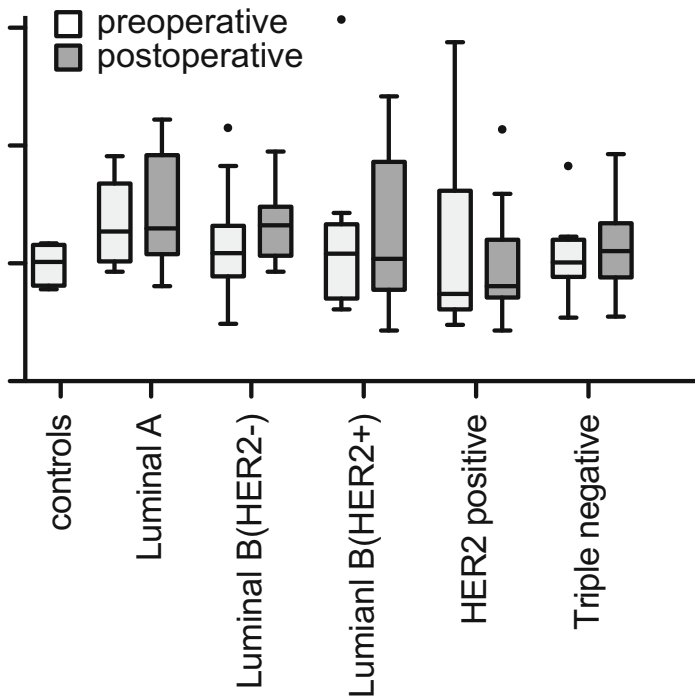


weak correlation between perlecan expression in the stroma and tumour grade was evident, with high grade tumours having a stronger expression of perlecan thus indicating an altered expression during tumour cell differentiation.

Some interesting differences were observed in terms for ER+ and ER- BC. The mRNA expression of different matrix degrading enzymes correlated significantly with perlecan mRNA and this correlation was sustained in the ER+ tumours but was, for many MMP's, lost in the ER- tumours. In the ER+ tumours a significantly higher level of perlecan mRNA was observed, and the same was also seen in plasma from patients with ER+ BC. Xiong et al. have shown that miRNA, in this case miR-22, is a direct regulator of the gene (ESR1) encoding the oestrogen receptor. By knockdown of endogenous miR-22 in breast cancer cell lines the ER expression is elevated and this was also seen in surgical specimens of breast cancer [40]. miR-22 is also a target of the gene encoding perlecan and 3-fold downregulation of miR22 duplicated the expression of perlecan [41]. These results points to that miR-22 can be a possible regulatory mechanism between perlecan and the ER status of the tumour. Pompei et al. have shown that oestrogen pharmacologically administered to castrated rats led to an increased level of perlecan in the carotid walls [42], and in rat mammary tissue, estradiol benzoate in combinations with medroxyprogesterone acetate, induced perlecan production and increased breast tissue proliferation [43]. These reports further support that oestrogen and perlecan are connected to each other. In tissue staining of perlecan protein the same was not observed, which could be due to the small cohort size, but also an overall strong staining of perlecan in both ER- and ER+ breast cancer stroma. No obvious correlation of perlecan expression with known prognostic biomarkers of $\mathrm{BC}$ was observed, nor with the molecular subtype of the tumour. This analysis is limited by the small size of the cohort and cannot thus be addressed with certainty. Furthermore, the source of the high expression of perlecan in breast cancer stroma remains elusive.

\section{Conclusions}

Perlecan synthesis and expression is altered during BC development and could be regulated in an oestrogen-dependent manner. Future studies should be focused establishing a prognostic value in $\mathrm{BC}$ using larger cohorts with longer follow up.

Acknowledgements The authors would like to acknowledge the expert help of Anette Berglund with histology.

Funding information Open access funding provided by Umea University. This study was funded by grants from Västerbotten County Council (to M.S. and M.J.) and Cancerforskningsfonden Norrland (to M.S.)

\section{Compliance with Ethical Standards}

Conflict of Interest The authors have no conflict of interest.

Open Access This article is licensed under a Creative Commons Attribution 4.0 International License, which permits use, sharing, adaptation, distribution and reproduction in any medium or format, as long as you give appropriate credit to the original author(s) and the source, provide a link to the Creative Commons licence, and indicate if changes were made. The images or other third party material in this article are included in the article's Creative Commons licence, unless indicated otherwise in a credit line to the material. If material is not included in the article's Creative Commons licence and your intended use is not permitted by statutory regulation or exceeds the permitted use, you will need to obtain permission directly from the copyright holder. To view a copy of this licence, visit http://creativecommons.org/licenses/by/4.0/.

\section{References}

1. Sorlie T, Perou CM, Tibshirani R, Aas T, Geisler S, Johnsen H, et al. Gene expression patterns of breast carcinomas distinguish tumor subclasses with clinical implications. Proc Natl Acad Sci U S A. 2001;98(19):10869-74. https://doi.org/10.1073/pnas.191367098.

2. Pietras K, Ostman A. Hallmarks of cancer: interactions with the tumor stroma. Exp Cell Res. 2010;316(8):1324-31. https://doi. org/10.1016/j.yexcr.2010.02.045.

3. Dvorak HF. Tumors: wounds that do notheal. Similarities between tumor stroma generation and wound healing. N Engl J Med. 1986;315(26): 1650-9. https://doi.org/10.1056/NEJM198612253152606.

4. Insua-Rodriguez J, Oskarsson T. The extracellular matrix in breast cancer. Adv Drug Deliv Rev. 2016;97:41-55. https://doi.org/10. 1016/j.addr.2015.12.017.

5. Hassell JR, Robey PG, Barrach HJ, Wilczek J, Rennard SI, Martin GR. Isolation of a heparan sulfate-containing proteoglycan from basement membrane. Proc Natl Acad Sci U S A. 1980;77(8):4494-8.

6. Hopf M, Gohring W, Kohfeldt E, Yamada Y, Timpl R. Recombinant domain IV of perlecan binds to nidogens, laminin-nidogen complex, fibronectin, fibulin-2 and heparin. Eur J Biochem. 1999;259(3):917-25.

7. Yurchenco PD, Schittny JC. Molecular architecture of basement membranes. FASEB J. 1990;4(6):1577-90.

8. Myers JC, Dion AS, Abraham V, Amenta PS. Type XV collagen exhibits a widespread distribution in human tissues but a distinct localization in basement membrane zones. Cell Tissue Res. 1996;286(3): 493-505.

9. Saarela J, Rehn M, Oikarinen A, Autio-Harmainen H, Pihlajaniemi $\mathrm{T}$. The short and long forms of type XVIII collagen show clear tissue specificities in their expression and location in basement membrane zones in humans. Am J Pathol. 1998;153(2):611-26. https://doi.org/10.1016/S0002-9440(10)65603-9.

10. Hayashi K, Madri JA, Yurchenco PD. Endothelial cells interact with the core protein of basement membrane perlecan through beta 1 and beta 3 integrins: an adhesion modulated by glycosaminoglycan. J Cell Biol. 1992;119(4):945-59.

11. Noonan DM, Fulle A, Valente P, Cai S, Horigan E, Sasaki M, et al. The complete sequence of perlecan, a basement membrane heparan sulfate proteoglycan, reveals extensive similarity with laminin a chain, low density lipoprotein-receptor, and the neural cell adhesion molecule. J Biol Chem. 1991;266(34):22939-47.

12. Vigny M, Ollier-Hartmann MP, Lavigne M, Fayein N, Jeanny JC, Laurent M, et al. Specific binding of basic fibroblast growth factor to basement membrane-like structures and to purified heparan 
sulfate proteoglycan of the EHS tumor. J Cell Physiol. 1988;137(2): 321-8. https://doi.org/10.1002/jcp.1041370216.

13. Sharma B, Handler M, Eichstetter I, Whitelock JM, Nugent MA, Iozzo RV. Antisense targeting of perlecan blocks tumor growth and angiogenesis in vivo. J Clin Invest. 1998;102(8):1599-608. https:// doi.org/10.1172/JCI3793.

14. Whitelock JM, Murdoch AD, Iozzo RV, Underwood PA. The degradation of human endothelial cell-derived perlecan and release of bound basic fibroblast growth factor by stromelysin, collagenase, plasmin, and heparanases. J Biol Chem. 1996;271(17):10079-86.

15. Datta MW, Hernandez AM, Schlicht MJ, Kahler AJ, DeGueme AM, Dhir R, et al. Perlecan, a candidate gene for the CAPB locus, regulates prostate cancer cell growth via the sonic hedgehog pathway. Mol Cancer. 2006;5:9. https://doi.org/10.1186/1476-4598-5-9.

16. Nugent MA, Nugent HM, Iozzo RV, Sanchack K, Edelman ER. Perlecan is required to inhibit thrombosis after deep vascular injury and contributes to endothelial cell-mediated inhibition of intimal hyperplasia. Proc Natl Acad Sci U S A. 2000;97(12):6722-7.

17. Farach-Carson MC, Warren CR, Harrington DA, Carson DD. Border patrol: insights into the unique role of perlecan/heparan sulfate proteoglycan 2 at cell and tissue borders. Matrix biology : journal of the International Society for Matrix Biology. 2013. https://doi.org/10.1016/j.matbio.2013.08.004.

18. Mongiat M, Sweeney SM, San Antonio JD, Fu J, Iozzo RV. Endorepellin, a novel inhibitor of angiogenesis derived from the C terminus of perlecan. J Biol Chem. 2003;278(6):4238-49. https://doi.org/10.1074/jbc.M210445200.

19. Willis CD, Poluzzi C, Mongiat M, Iozzo RV. Endorepellin lamininlike globular 1/2 domains bind Ig3-5 of vascular endothelial growth factor (VEGF) receptor 2 and block pro-angiogenic signaling by VEGFA in endothelial cells. FEBS J. 2013;280(10):2271-84. https://doi.org/10.1111/febs.12164.

20. Douglass S, Goyal A, Iozzo RV. The role of perlecan and endorepellin in the control of tumor angiogenesis and endothelial cell autophagy. Connect Tissue Res. 2015;56(5):381-91. https:// doi.org/10.3109/03008207.2015.1045297.

21. Gonzalez EM, Reed CC, Bix G, Fu J, Zhang Y, Gopalakrishnan B, et al. BMP-1/Tolloid-like metalloproteases process endorepellin, the angiostatic C-terminal fragment of perlecan. J Biol Chem. 2005;280(8):7080-7. https://doi.org/10.1074/jbc.M409841200.

22. Cailhier JF, Sirois I, Laplante P, Lepage S, Raymond MA, Brassard $\mathrm{N}$, et al. Caspase- 3 activation triggers extracellular cathepsin $\mathrm{L}$ release and endorepellin proteolysis. J Biol Chem. 2008;283(40): 27220-9. https://doi.org/10.1074/jbc.M801164200.

23. Institute NC. https://portal.gdc.cancer.gov. Genomic Data Commons Data Portal. 2018;Accessed 13 June 2018.

24. Goldhirsch A, Winer EP, Coates AS, Gelber RD, Piccart-Gebhart M, Thurlimann B, et al. Personalizing the treatment of women with early breast cancer: highlights of the St Gallen international expert consensus on the primary therapy of early breast Cancer 2013. Annals of oncology : official journal of the European Society for Medical Oncology / ESMO. 2013;24(9):2206-23. https://doi.org/10.1093/annonc/mdt303.

25. Kohrmann A, Kammerer U, Kapp M, Dietl J, Anacker J. Expression of matrix metalloproteinases (MMPs) in primary human breast cancer and breast cancer cell lines: new findings and review of the literature. BMC Cancer. 2009;9:188. https://doi.org/ 10.1186/1471-2407-9-188.

26. Kalscheuer S, Khanna V, Kim H, Li S, Sachdev D, DeCarlo A, et al. Discovery of HSPG2 (Perlecan) as a therapeutic target in triple negative breast Cancer. Sci Rep. 2019;9(1):12492. https://doi.org/ 10.1038/s41598-019-48993-6.

27. Fernandez-Vega I, Garcia O, Crespo A, Castanon S, Menendez P, Astudillo A, et al. Specific genes involved in synthesis and editing of heparan sulfate proteoglycans show altered expression patterns in breast cancer. BMC Cancer. 2013;13:24. https://doi.org/10.1186/ 1471-2407-13-24.
28. Mathiak M, Yenisey C, Grant DS, Sharma B, Iozzo RV. A role for perlecan in the suppression of growth and invasion in fibrosarcoma cells. Cancer Res. 1997;57(11):2130-6.

29. Marchisone C, Del Grosso F, Masiello L, Prat M, Santi L, Noonan DM. Phenotypic alterations in Kaposi's sarcoma cells by antisense reduction of perlecan. Pathol Oncol Res. 2000;6(1):10-7.

30. Gialeli C, Theocharis AD, Karamanos NK. Roles of matrix metalloproteinases in cancer progression and their pharmacological targeting. FEBS J. 2011;278(1):16-27. https://doi.org/10.1111/j. 1742-4658.2010.07919.x

31. Poluzzi C, Casulli J, Goyal A, Mercer TJ, Neill T, Iozzo RV Endorepellin evokes autophagy in endothelial cells. J Biol Chem. 2014;289(23):16114-28. https://doi.org/10.1074/jbc.M114.556530.

32. White E. Deconvoluting the context-dependent role for autophagy in cancer. Nat Rev Cancer. 2012;12(6):401-10. https://doi.org/10. 1038/nrc3262.

33. Mishra M, Chandavarkar V, Naik VV, Kale AD. An immunohistochemical study of basement membrane heparan sulfate proteoglycan (perlecan) in oral epithelial dysplasia and squamous cell carcinoma. Journal of oral and maxillofacial pathology : JOMFP. 2013;17(1):31-5. https://doi.org/10.4103/0973-029X.110704.

34. Iozzo RV, Cohen IR, Grassel S, Murdoch AD. The biology of perlecan: the multifaceted heparan sulphate proteoglycan of basement membranes and pericellular matrices. The Biochemical journal. 1994;302(Pt 3):625-39.

35. Ritchey ER, Code K, Zelinka CP, Scott MA, Fischer AJ. The chicken cornea as a model of wound healing and neuronal re-innervation. Mol Vis. 2011;17:2440-54.

36. Sabit H, Tsuneyama K, Shimonishi T, Harada K, Cheng J, Ida H, et al. Enhanced expression of basement-membrane-type heparan sulfate proteoglycan in tumor fibro-myxoid stroma of intrahepatic cholangiocarcinoma. Pathol Int. 2001;51(4):248-56.

37. Aviezer D, Hecht D, Safran M, Eisinger M, David G, Yayon A. Perlecan, basal lamina proteoglycan, promotes basic fibroblast growth factor-receptor binding, mitogenesis, and angiogenesis. Cell. 1994;79(6):1005-13.

38. Spivak-Kroizman T, Lemmon MA, Dikic I, Ladbury JE, Pinchasi D, Huang J, et al. Heparin-induced oligomerization of FGF molecules is responsible for FGF receptor dimerization, activation, and cell proliferation. Cell. 1994;79(6):1015-24.

39. Saksela O, Moscatelli D, Sommer A, Rifkin DB. Endothelial cellderived heparan sulfate binds basic fibroblast growth factor and protects it from proteolytic degradation. J Cell Biol. 1988;107(2):743-51.

40. Xiong J, Yu D, Wei N, Fu H, Cai T, Huang Y, et al. An estrogen receptor alpha suppressor, microRNA-22, is downregulated in estrogen receptor alpha-positive human breast cancer cell lines and clinical samples. FEBS J. 2010;277(7):1684-94. https://doi.org/10. 1111/j.1742-4658.2010.07594.x.

41. Eisenberg I, Eran A, Nishino I, Moggio M, Lamperti C, Amato AA, et al. Distinctive patterns of microRNA expression in primary muscular disorders. Proc Natl Acad Sci U S A. 2007;104(43):1701621. https://doi.org/10.1073/pnas.0708115104.

42. Pompei LM, Steiner ML, Theodoro TR, Souza PZ, Romanini AC, Coulson-Thomas V, et al. Effect of estrogen therapy on vascular perlecan and metalloproteinases 2 and 9 in castrated rats. Climacteric. 2013;16(1):147-53. https://doi.org/10.3109/ 13697137.2012.667173.

43. Cunha EP, Pompei LM, Theodoro TR, Steiner ML, Silva VF, Silveira $\mathrm{ER}$, et al. Is expression of rat breast matrix components influenced by estrogen, progestins and tibolone? Climacteric. 2015;18(4):523-7. https://doi.org/10.3109/13697137.2015.1007122.

Publisher's Note Springer Nature remains neutral with regard to jurisdictional claims in published maps and institutional affiliations. 